TECHNICAL TRANSACTIONS 10/2017

CZASOPISMO TECHNICZNE 10/2017

MECHANICS

DOI: $10.4467 / 2353737$ XCT.17.184.7292

Hassan Momeni (hassan.momeni@hvl.no)

Department of Mechanical and Marine Engineering, Western Norway University of Applied Sciences

\title{
Mariusz Domagala
}

Institute of Applied Informatics, Faculty of Mechanical Engineering, Cracow University

of Technology

\section{CFD SIMUlations OF HYDROFOILS FOR TIDAL TURBINES}

SYMULACJE CFD PROFILI TURBIN WYKORZYSTUJĄCYCH PŁYWY MORSKIE

\begin{abstract}
Tidal energy might be extracted in a very similar way as the wind one by using turbines. However, due to environmental conditions, unsteady nature of tidal currents and wave activity, tidal turbines have to fulfill very demanding requirements. Such turbines might be structurally similar to wind turbines, but due to a different medium, the key issue is extracting tidal energy in the most effective way. This paper presents a way in which CFD tools may be used for selecting hydrofoil for tidal turbines.
\end{abstract}

Keywords: CFD, tidal turbine

\section{Streszczenie}

Energia plywów morskich może być pozyskiwana w podobny sposób jak energia wiatrowa. Jednakże ze względu na warunki środowiskowe oraz zmieniające się warunki pracy turbiny muszą spełniać bardzo wysokie wymagania. Mogą one być podobnie zbudowane jak wiatrowe, ale ze względu na inny rodzaj medium kluczową sprawą jest uzyskiwanie energii w najbardziej efektywny sposób. W referacie przedstawiono wykorzystanie narzędzi CFD do doboru odpowiedniego profilu lopat wirnika turbiny.

Słowa kluczowe: CFD, turbina wykorzystująca pływy morskie 


\section{Introduction}

Demand for electrical power rises every year even due to a significant improvement of power efficiency. Increased power demand, if covered by traditional energy sources, will lead to enormous pollution. Therefore, renewable energy may be a solution. Except for wind, water and solar power, tidal energy is gaining more and more interest, and in comparison to wind power, it has higher energy density and predictability. Tidal energy may be extracted in a similar way as wind power. However, operating conditions, unsteady tidal currents and wave activity are the reasons why tidal turbines have to meet very high requirements. Another issue is a very high cost of their installation and maintenance. Tidal energy is a relatively young branch of renewable energy, but some practical applications already exist. Fig. 1 and 2 show examples of tidal turbine already in use.

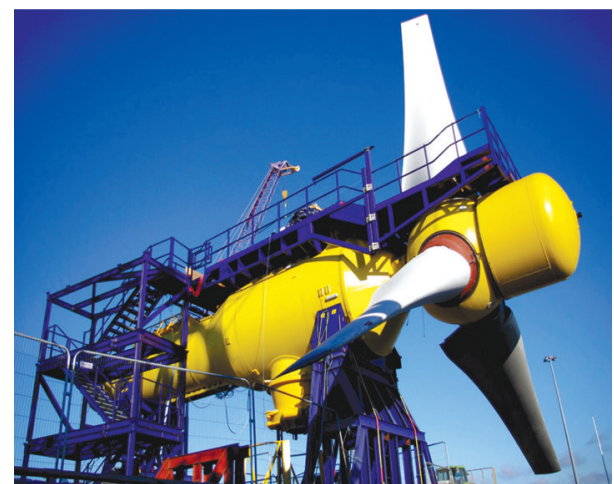

Fig. 1. Fig. 1. A horizontal tidal turbine by ALSTOM

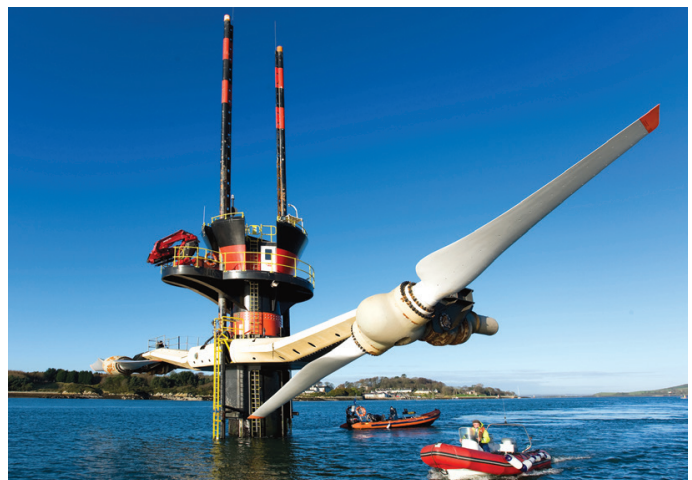

Fig. 2. Fig. 2. A tidal turbine installed in Northern Ireland

A lot of research has been conducted on tidal energy [1-3] for various tidal turbines: horizontal or vertical, floating on the sea surface or anchored to sea bed, or even with additional diffusers to increase turbine efficiency [4]. The design of a tidal turbine is still a challenge. The key issue is a proper selection of a hydrofoil and blade shape. Due to a different medium, blade element momentum (BEM) may not be directly implemented to a tidal turbine because of cavitation phenomenon which might be problematic to predict. Additionally, typical airfoils used in wind turbines may not extract tidal energy efficiently enough. Grasso F. [5] claims that efficiency of tidal turbines may be used in tailored hydrofoil. The Computational Fluid Dynamics (CFD) method, whose application in marine and wind turbine is presented in detail in work [6], brings a new quality to the design of tidal turbines. Design tools like CAE systems allow for investigating flow phenomena and evaluating load caused by water flow. This paper presents the use of CFD method for the evaluation of hydrodynamic efficiency of a typical airfoil. For three selected airfoils NACA 4418, 4416 and 4412, drag and lift forces were evaluated for the same Reynolds number. 


\section{CFD simulation of hydrofoils}

The key factor for extracting energy is a hydrofoil and its hydrodynamic efficiency. For the evaluation of this factor, tools using BEM (blade element theory) like XFoil can be used. However, much more information can be obtained from CFD simulations, which use numerical solutions of flow governing equations. These are: continuity equation which is also called mass conservation equation:

$$
\frac{\partial \rho}{\partial t}+\nabla \cdot(\rho \mathbf{U})=S_{M}
$$

and the momentum conservation equation:

$$
\frac{\partial(\rho \mathbf{U})}{\partial t}+\nabla \cdot(\rho \mathbf{U} \times \mathbf{U})=-\nabla p+\nabla \cdot \tau+F+\rho g
$$

where $\tau$ is the stress tensor:

$$
\tau=\mu\left(\nabla \mathbf{U}+(\nabla \mathbf{U})^{T}-\frac{2}{3} \delta \nabla \mathbf{U}\right)
$$

The above equations might be completed with the energy equation, which is as follows:

$$
\frac{\partial(\rho h)}{\partial t}-\frac{\partial \rho}{\partial t}+\nabla \cdot(\rho \mathbf{U h})=\nabla \cdot(\lambda \nabla T)+\nabla \cdot(\mathbf{U} \cdot \tau)+\mathbf{U} \cdot F+S_{E}
$$

where:

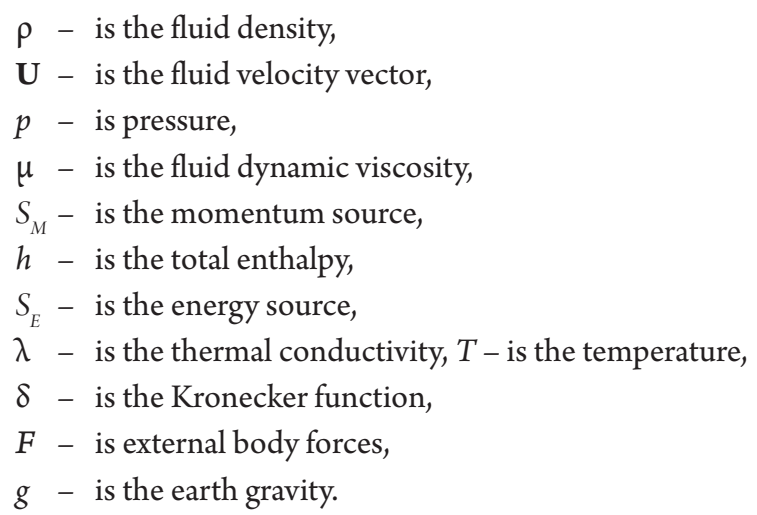

Despite the fact that water current may reach relatively small velocity (pick value round $4 \mathrm{~m} / \mathrm{s}$ ), the flow around a hydrofoil is turbulent, which means that is unsteady and random by nature. Solving N-S equations (continuity and momentum conservation) in a general form for turbulent flows is very time consuming and inefficient. But it does not mean that turbulent flows are not able to be simulated. One of the approaches are Reynolds Averaging N-S equations (RANS), which define velocity as a mean value and fluctuations of this value. RANS define each value as a mean value and its fluctuations. In case of velocity we have: 
where:

$$
u_{i}=\bar{u}_{i}+u_{i}^{\prime}
$$

$\bar{u}_{i}-$ is the mean velocity value,

$u_{i}^{\prime}$ - is the fluctuating velocity, stands for velocity component.

After inserting Eq. (7) to N-S equations Eq. $(1,2)$, we obtain RANS equations:

$$
\begin{gathered}
\frac{\partial \rho}{\partial t}+\frac{\partial \rho}{\partial x_{i}}\left(\rho u_{i}\right)=0 \\
\frac{\partial \rho}{\partial t}\left(\rho u_{i}\right)+\frac{\partial \rho}{\partial x_{j}}\left(\rho u_{i} u_{j}\right)=-\frac{\partial p}{\partial x_{i}}+\frac{\partial}{\partial x_{j}}\left[\mu\left(\frac{\partial u_{i}}{\partial x_{j}}+\frac{\partial u_{j}}{\partial x_{i}}-\frac{2}{3} \delta_{i j} \frac{\partial u_{i}}{\partial x_{i}}\right)\right]+\frac{\partial}{\partial x_{j}}\left(-\rho \overline{u_{i} u_{j}}\right)
\end{gathered}
$$

The additional term which appears in Eq $(7)-\rho \overline{u_{i} u_{j}}$ represents the effects of turbulence (called Reynolds stress) and makes the set of Eq (6) and Eq (7) not closed, therefore it has to be modeled. A common method to close these equations is the Boussinesq hypothesis:

$$
-\rho \overline{u_{i} u_{j}}=\mu_{t}\left(\frac{\partial u_{i}}{\partial x_{j}}+\frac{\partial u_{j}}{\partial x_{i}}\right)-\frac{2}{3} \delta_{i j}\left(\rho k+\mu_{t} \frac{\partial u_{k}}{\partial x_{k}}\right)
$$

and the use of turbulence models.

CFD simulations not only allow for gaining information about pressure or velocity distribution and turbulence intensity, but also for evaluating drag and lift forces which define the turbine efficiency. In this work, three airfoils NACA 4418, 4416 and 4412 were selected for CFD simulations. All the airfoils were examined at the same Reynolds number (approx. 100000 ) for $2 \mathrm{D}$ angle of attack. The simulations were conducted in the Ansys CFX code with the following assumptions: the flow was turbulent (SST turbulence model), at steady state conditions with typical sea water properties at the depth of $10 \mathrm{~m}$, the model was in thermal equilibrium, the airfoil had an ideal smooth surface and the water was not able to slip on the surface.

\section{Object of study}

The selection of a proper hydrofoil is not an easy task. A typical airfoil used in wind turbine may not be efficient enough and may cause cavitation, which is difficult to predict. Therefore, in this work three typical NACA airfoils were used in CFD simulation to estimate their lift and drag forces. Those were NACA 4418, 4416 and 4412 airfoils. Airfoil profiles were created based on coordinates extracted from available calculators [7] in the Creo Parametric system as $2 \mathrm{D}$ models.

All of them were tested in the same conditions, with the same grid size and for various values of angle of attack but for constant Reynolds number. During water flow over the 
hydrofoil, the lift force (L) is generated along with the drag force (D). The product of those two forces is a total force that appears on the turbine blade during fluid flow. Magnitude of both forces depends on the angle of attack. The ratio of lift coefficient to drag coefficient is one of the factors that describe hydrodynamic efficiency.

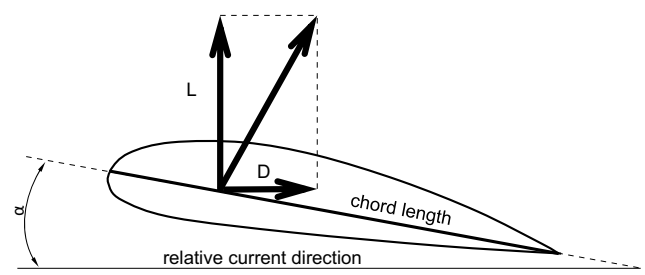

Fig. 3. Forces acting on a hydrofoil

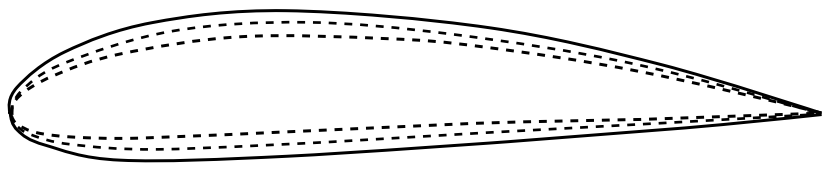

NACA 4418
NACA 4416
NACA 4412

Fig. 4. Investigated airfoils

\section{Results of CFD simulations}

The CFD simulations were conducted in the Ansys CFX code, as 2D models. The simulations allowed for investigating velocity and pressure distribution as well as the lift and drag forces. The details of CFD results are presented in Figs. 5-7. These figures show velocity and pressure distribution for the angle of attack $\alpha=0^{\circ}$. Figures 8-10 show the ratio of lift coefficient to drag coefficient for various angles of attack, which range from $-10^{\circ}$ to $14^{\circ}$.

The lift and drag forces which were extracted from the CFD simulations, were approximated and presented in the figures below in the function of an angle of attack. The analysis of presented values shows that the last two profiles (4416 and 4412) reach much slower values of the CL/CD ratio than airfoil 4418, for which maximal values are between $-0.5^{\circ}$ to $6^{\circ}$.

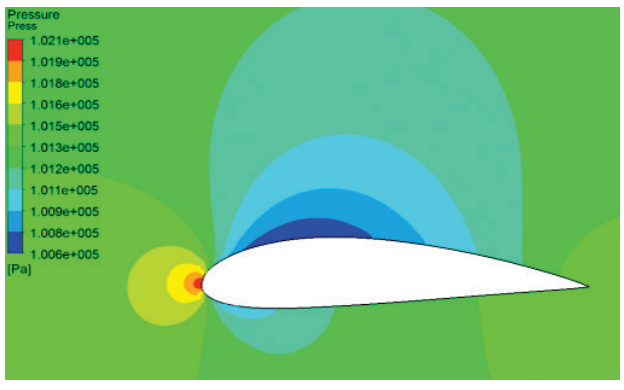

Fig. 5a. NACA 4418: pressure distribution

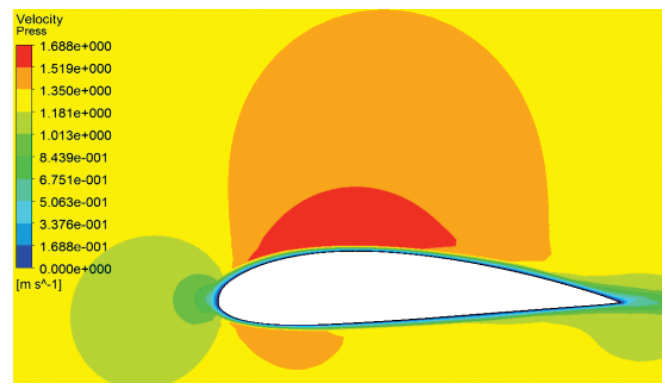

Fig. 5b. NACA 4418: velocity distribution 


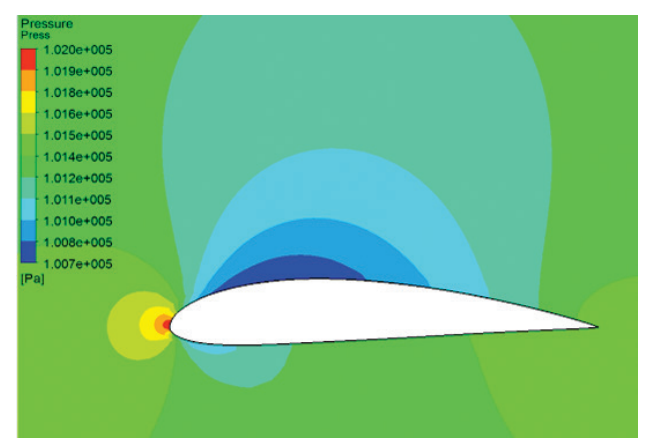

Fig. 6a. NACA 4416: pressure distribution

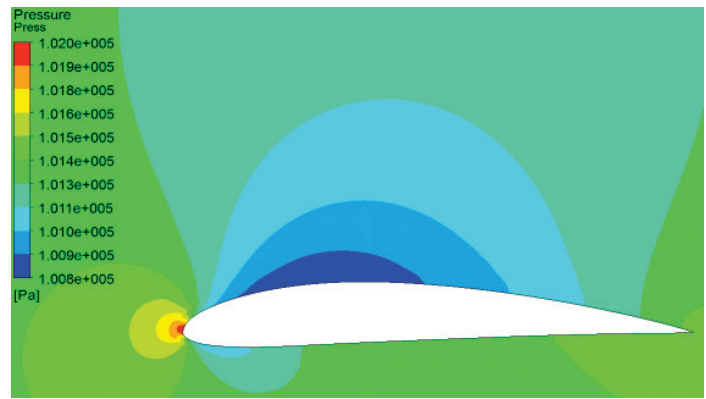

Fig. 7a. NACA 4412: pressure distribution

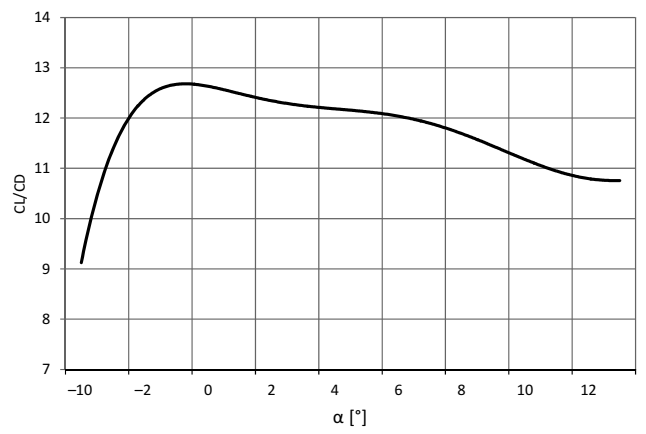

Fig. 8. CL/CD ratio for NACA 4418

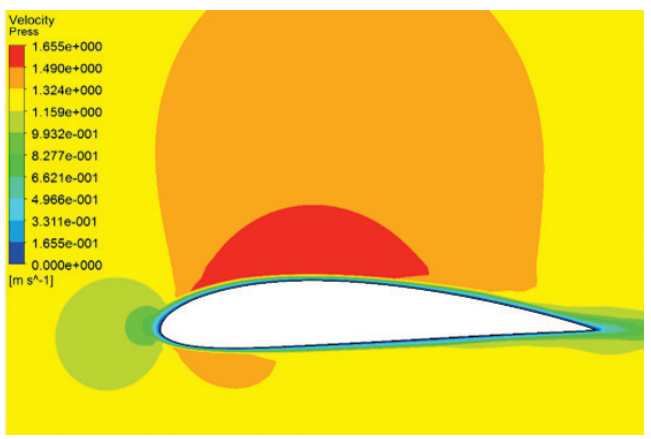

Fig. 6b. NACA 4418: velocity distribution

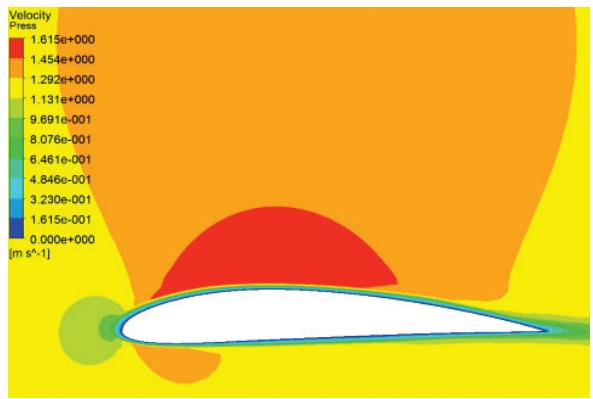

Fig. 7b. NACA 4418: velocity distribution

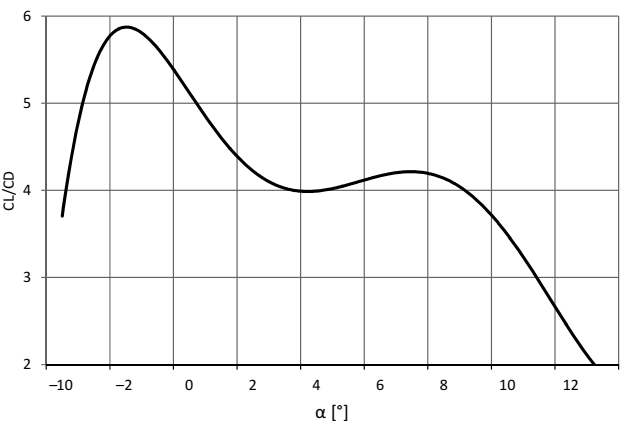

Fig. 9. CL/CD ratio for NACA 4416

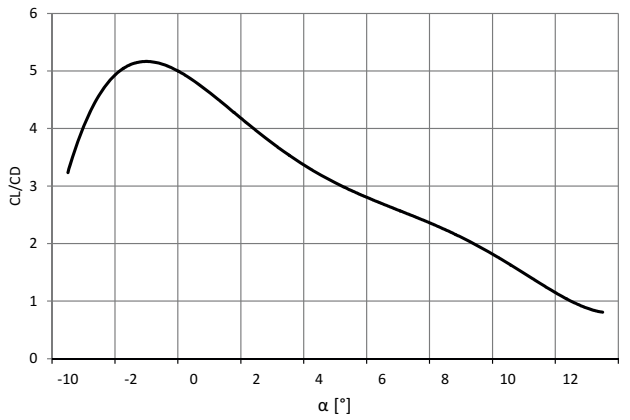

Fig. 10. CL/CD ratio for NACA 4412 


\section{Conclusions}

Tidal energy is gaining more and more interest in recent years and, in comparison to wind power, is very attractive due to its power density and predictability. On the other hand, tidal turbines have to meet much stronger requirements and their design is still a challenge. Therefore, CFD tools seem to be very promising design tools for tidal turbines. They allow for evaluating pressure and velocity distribution, extracting lift and drag forces and even predicting cavitation. They can be also used for the prediction of total load that may appear during water flow. CFD simulations may also be used for the optimization of hydrofoils or creation of hydrofoils which allow for extracting tidal energy in the most efficient way.

\section{References}

[1] Batten W.M.J., Bahaj A.S., Mollandb A.F., Chaplina J.R., The prediction of the hydrodynamic performance of marine current turbines, Renewable Energy, 33, 2008, 1085-1096.

[2] Batten W.M.J., Bahaj A.S., Mollandb A.F., Chaplina J.R., Hydrodynamics of marine current turbines, Renewable Energy, 31, 2006, 249-256.

[3] Bahaj A.S., Batten W.M.J., Chaplina J.R., Experimental verifications of numerical predictions for the hydrodynamic performance of horizontal axis marine current turbines, Renewable Energy, 32, 2007, 2479-2490.

[4] Mehmood N., Liang Z., Khan J., Diffuser Augmented Horizontal Axis Tidal Current Turbines, Research Journal of Applied Sciences, Engineering and Technology, 4(18), 2012, 3522-3532.

[5] Grasso F., Design and Optimization of Tidal turbine Airfoil, 29th AIAA Applied Aerodynamics Conference, 27-30 June 2011, Honolulu, HI, USA, AIAA, 2011-3816.

[6] Ferrer E., Montlaur A. eds., CFD for Wind and Tidal Offshore Turbines, Springer Tracts in Mechanical Engineering, Springer, 2015.

[7] http://airfoiltools.com.

[8] Bir G.S., Lawson M.J., Li Y., Structural Design of a Horizontal-Axis Tidal Current Turbine Composite Blade, ASME 30th International Conference on Ocean, Offshore, and Arctic Engineering Rotterdam, The Netherlands, June 19-24, 2011.

[9] Rafiuddin A.M., Blade sections for wind turbine and tidal current turbine applications-current status and future challenges, Int. J. Energy Res., 36, 2012, 829-844; published online 22 March 2012 in Wiley Online Library (wileyonlinelibrary.com). DOI: 10.1002/er.2912

[10] Zeiner-Gundersen D.H., Turbine design and field development concepts for tidal, ocean, and river applications, Energy Science and Engineering, 3(1), 2015, 27-42. 